insulin resistance in patients with non-insulin-dependent diabetes mellitus been ascribed to abnormal islet cell products or circulating insulin antagonists. In most cases it is thought to be caused by a combination of a decreased number of receptors and a postreceptor defect. The rationale for the present study was that, although the sequence of postreceptor events is not clear, a drug able to inhibit postreceptor degradation might promote the metabolic effects of insulin and overcome, at least in part, the insulin resistance. There is some precedence for this approach, as Blazar et al showed a dramatic decrease in the insulin resistance of a patient with insulin dependent diabetes mellitus after treatment with chloroquine. ${ }^{8}$

In the control group administration of chloroquine had negligible effects on glucose homoeostasis and plasma insulin and $\mathrm{C}$ peptide concentrations. This supports the findings of Philips $e t$ al, who showed that, unlike quinine, which can produce severe hypoglycaemia, infusion of chloroquine and other synthetic antimalarial drugs has no appreciable effect on plasma glucose and insulin concentrations. ${ }^{9}$ The diabetic patients in this study experienced significant changes in glucose tolerance after treatment with chloroquine, the largest changes occurring in those who showed the greatest glucose intolerance before treatment. These changes represent a median decrease of $8.9 \%$ (range $0.4 \%$ to $12 \cdot 1 \%$ ) in the glucose intolerance of this group of patients.

The improvement in glucose tolerance in the patients with noninsulin-dependent diabetes mellitus was reflected by a significant increase in plasma insulin concentration during the glucose tolerance test. The fact that the $\mathrm{C}$ peptide concentrations did not show a similar increase argues against increased output of insulin as a mode of action of the chloroquine. The insulin assay used in this study also detects proinsulin, and the raised values may therefore reflect increased circulatory proinsulin. This would imply that chloroquine had interfered with the proteolytic conversion of proinsulin to insulin in the Golgi apparatus of the islet cells and would be expected to have a deleterious effect on glucose homoeostasis rather than the beneficial effect shown here.

Although the glucose tolerance improved significantly on glucose challenge, there was no apparent change in the basal fasting glucose concentration. This may be connected with the short duration of the treatment with chloroquine and is now being investigated. Whether or not the effect of chloroquine is hepatic or peripheral cannot be determined from this study; inhibition of intraligandosomal breakdown is certainly a possible mechanism.

Interestingly, in the controls and the one diabetic patient with near normal glucose tolerance chloroquine had negligible effects on glucose tolerance. This suggests that in non-diabetic subjects the normal homoeostatic mechanisms responsible for insulin-glucose regulation may compensate for perturbations in the insulin concentrations that may be caused by chloroquine and thus prevent the onset of hypoglycaemia.

The results of this study suggest that treatment of non-insulindependent diabetes mellitus with chloroquine or suitable analogues may provide a means of diabetic control that does not entail stimulation of pancreatic insulin production. In particular, our results suggest that chloroquine may be useful in diminishing postprandial hyperglycaemia in obese patients with non-insulindependent diabetes mellitus.

\section{References}

1 Field JB. Extraction of insulin by liver. Annu Rev Med 1973;24:309-14.

2 Caro JF, Muller G, Glennon JA. Insulin processing by the liver. $\mathcal{F}$ Biol Chem 1982;257:8459-66

3 Terris S, Hoffman C, Steiner DF. Mode of uptake and degradation of ${ }^{125} \mathrm{I}$-labelled insulin by isolated hepatocytes and H4 hepatoma cells. Can $\mathcal{F}$ Biochem 1979;57:459-68.

4 Dennis PA, Aronson NN. The effects of low temperature and chloroquine on ${ }^{125} \mathrm{I}$-insulin degradation by the perfused rat liver. Arch Biochem Biophys 1981;212:170-6.

5 Pease RJ, Smith GD, Peters TJ. Degradation of endocytosed insulin in rat liver is mediated by low density vesicles. Biochem $\mathcal{f}$ 1985;228:137-46.

6 Smith GD, Peters TJ. The localization in rat liver of alkaline phosphodiesterase to a discrete organelle implicated in ligand internalization. Biochim Biophys Acta 1982;716:24-30.

7 Kahn OR. Insulin resistance: a common feature of diabetes mellitus. $N$ Engl f Med 1986;315: 252-3.

8 Blazar BR, Whitley CB, Kitabchi AE, et al. In vivo chloroquine induced inhibition of insulin degradation in a diabetic patient with severe insulin resistance. Diabetes 1984;33:1133-7.

9 Philips RE, Looareesuwan S, White NJ, et al. Hypoglycaemia and antimalarial drugs: quinidine and release of insulin. BrMed $\mathcal{F}$ 1986;292:1319-21.

\title{
Effect of single high dose infusions of aminohydroxypropylidene diphosphonate on hypercalcaemia caused by cancer
}

\author{
BRIAN M J CANTWELL, ADRIAN L HARRIS
}

\begin{abstract}
Single intravenous infusions of $\mathbf{3 0} \mathbf{~ m g}$ aminohydroxypropylidene diphosphonate were given to 16 patients who had malignant hypercalcaemia to assess host tolerance and the effect on serum calcium concentration. Ten of these patients also received intravenous rehydration or corticosteroids, or both. The serum calcium concentrations decreased significantly after treatment with aminohydroxypropylidene diphosphonate. Ten patients became normocalcaemic (normal range, adjusted for serum
\end{abstract}

University Department of Clinical Oncology, Newcastle General Hospital, Newcastle upon Tyne NE4 6BE

BRIAN M J CANTWELL, MD, MRCP, lecturer in clinical oncology

ADRIAN L HARRIS, DPHIL, FRCP, professor of clinical oncology

Correspondence to: Dr Cantwell. albumin, $2 \cdot 25-2 \cdot 75 \mathrm{mmol} / \mathrm{l})$, two became hypocalcaemic, three showed decreases in serum calcium concentrations of more than $0.75 \mathrm{mmol} / \mathrm{l}$, and one showed a decrease of more than 0.55 $\mathrm{mmol} / \mathrm{l}$. Only one patient had a minimum concentration greater than $2.77 \mathrm{mmol} / \mathrm{l}$. Aminohydroxypropylidene diphosphonate was effective in metastatic and non-metastatic hypercalcaemia, and its hypocalcaemic effect was prolonged in some cases. There were no appreciable side effects.

Single high dose infusions of aminohydroxypropylidene diphosphonate could replace conventional daily lower dose infusions, but the optimum frequency of high dose infusions remains to be determined.

\section{Introduction}

Hypercalcaemia associated with malignancy was the most common type of hypercalcaemia identified in a large hospital survey. ${ }^{1}$ The treatment of hypercalcaemia associated with malignancy may be 
difficult, and there is no universally effective and specific calcium lowering agent.

Recently, encouraging results have been shown for the diphosphonates, including aminohydroxypropylidene diphosphonace. ${ }^{2}$ Intravenous aminohydroxypropylidene diphosphonate is effective, when compared with volume repletion, ${ }^{3}$ mithramycin, corticosteroids, and calcitonin, ${ }^{4}$ at treating hypercalcaemia caused by cancer. It has previously been given by daily intravenous infusion, doses ranging from $1.75 \mathrm{mg}$ to $30 \mathrm{mg}$, and most patients have been given $15 \mathrm{mg}$ daily over several days. ${ }^{3}{ }^{4}$ Ralston et al found that serum calcium concentrations decreased considerably two days after the start of daily infusions of aminohydroxypropylidene diphosphonate, but about half of their patients remained mildly hypercalcaemic. ${ }^{4}$

Intravenous infusion of $15 \mathrm{mg}$ aminohydroxypropylidene diphosphonate with intravenous saline and salmon calcitonin daily for six days has been effective in reducing serum calcium concentrations in eight patients suffering from hypercalcaemia associated with cancer. ${ }^{5}$ Our previous work ${ }^{6}$ led us to examine aminohydroxypropylidene diphosphonate given as a single high dose bolus to determine if this could replace daily lower dose intravenous infusions to treat malignant hypercalcaemia.

\section{Patients and methods}

Sixteen adult patients who had malignant hypercalcaemia, comprising five women with breast cancer and 11 men with other cancers, were treated. All but three had evidence of bone metastases in skeletal radiographs and isotope skeletal scans. The median age of the patients was 59 (range 31 to 70 ). Two patients had previously received treatment for hypercalcaemia: one had received intravenous rehydration, frusemide, and corticosteroids and the other intravenous rehydration, frusemide, and calcitonin. Despite these treatments both remained biochemically and symptomatically hypercalcaemic.

Aminohydroxypropylidene diphosphonate $30 \mathrm{mg}$ in $500 \mathrm{ml}$ normal saline was infused intravenously over two hours. Ten patients were also given other potentially hypocalcaemic treatment. Intravenous rehydration with three or more litres of normal saline daily was given to nine patients; of these, four were randomised to receive corticosteroids as well (table). In addition, one patient received corticosteroids alone.

Biochemical measurements were made with an autoanalyser (Technicon). The serum calcium concentrations were corrected for serum albumin using serum albumin concentrations measured simultaneously with serum calcium. ${ }^{7}$ The paired Wilcoxon test was used for statistical analysis.

After the early effects of aminohydroxypropylidene diphosphonate had been determined some patients started or changed specific anticancer treatments-for example, radiotherapy, hormone treatment, cytotoxic chemotherapy, or a combination of these.

\section{Results}

Serum calcium concentrations decreased significantly $(p<0.001)$ in all patients after treatment with aminohydroxypropylidene diphosphonate when pretreatment concentrations were compared with the lowest concentrations after treatment (table). Normal calcium concentrations were restored in 10 patients, including four of the six who received only treatment with aminohydroxypropylidene diphosphonate, and hypocalcaemia occurred in two. Calcium concentrations decreased to just above the normal range $(2 \cdot 76,2 \cdot 76$, and $2 \cdot 77 \mathrm{mmol} / \mathrm{l}$; normal range $2 \cdot 25-2 \cdot 75 \mathrm{mmol} / \mathrm{l})$ in a further three patients. One of two patients resistant to previous treatment became normocalcaemic after treatment with aminohydroxypropylidene diphosphonate. Of the four patients not achieving normal calcium concentrations, one showed a decrease of more than $0.55 \mathrm{mmol} / \mathrm{l}$, three showed decreases of more than $0.75 \mathrm{mmol} / 1$, and only one patient had a minimum serum calcium concentration greater than $2.77 \mathrm{mmol} / \mathrm{l}$ after treatment with aminohydroxypropylidene diphosphonate. Serum calcium concentrations fell below the normal range in two patients but returned to normal in 24 hours without any clinical signs of hypocalcaemia being observed.

The time taken to reach normal or minimum serum calcium concentrations was one to nine days after treatment with aminohydroxypropylidene diphosphonate. Individual serum calcium concentrations plotted against time generally indicated a decline in concentrations up to eight days after treatment (figure). Two patients (13\%) achieved normal or minimum concentrations within one day and four patients (the modal group) on the third day; by the fourth day after treatment eight patients $(50 \%)$ had achieved normal or minimum concentrations.
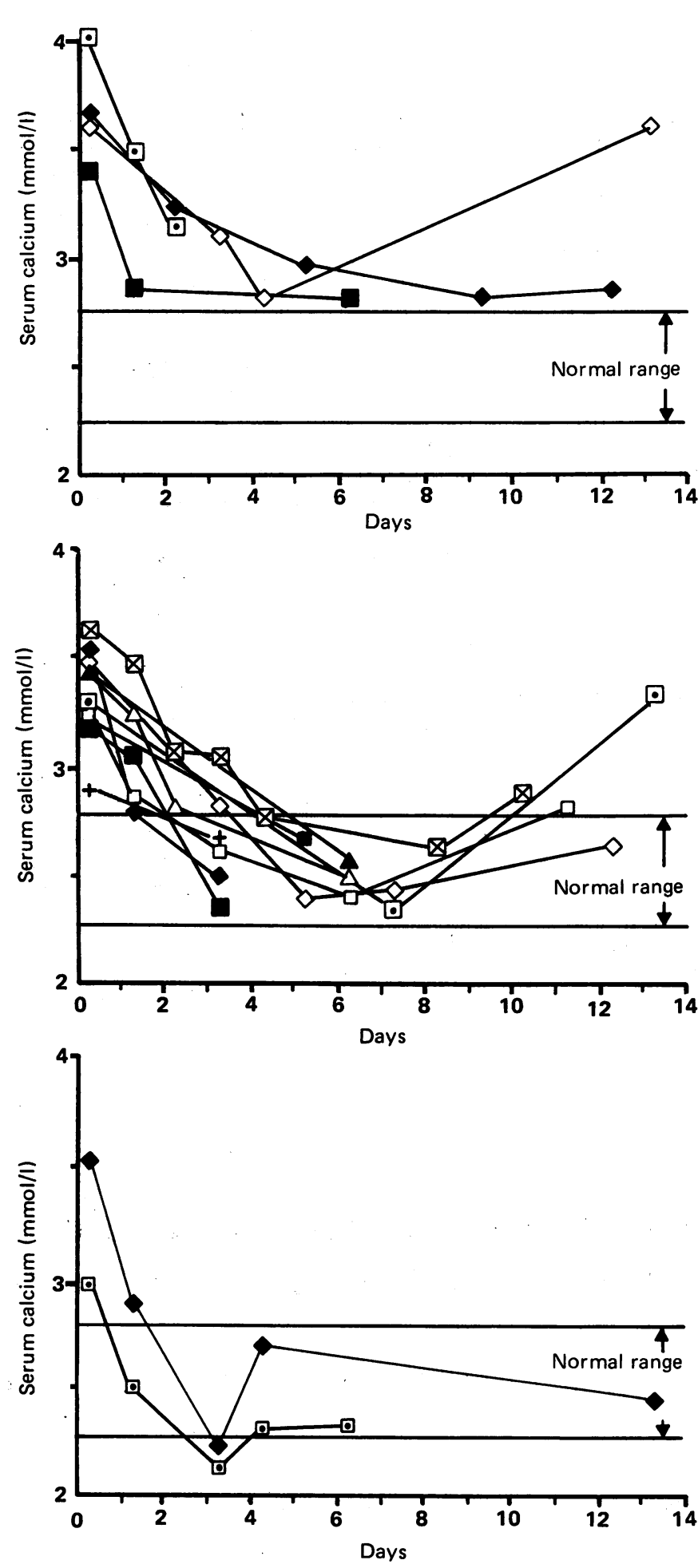

Serum calcium concentrations after a single intravenous infusion of $30 \mathrm{mg}$ aminohydroxypropylidene diphosphonate in four patients remaining hyper- $-\mathrm{W}$ calcaemic (top), 10 patients who achieved normocalcaemia (middle), and twoo patients who briefly became hypocalcaemic (bottom).

Despite initial decreases of more than $0.75 \mathrm{mmol} / 1$ in their serum calcium $\stackrel{8}{+}$ concentrations two patients became appreciably hypercalcaemic again on 0 day 13. Recurrent hypercalcaemia was detected at 10,11,13,55, and 690 days' follow up in five patients who became normocalcaemic after the first infusion of aminohydroxypropylidene diphosphonate. Worsening hyper-市 calcaemia $(>3.0 \mathrm{mmol} / \mathrm{l})$ was detected at 13,24 , and 47 days in three patients who did not achieve normocalcaemia after the first infusion. Five patients were retreated with $30 \mathrm{mg}$ aminohydroxypropylidene diphosphonate in a 8 two hour intravenous infusion, and decreases in serum calcium concentra-0 tions of $0 \cdot 29-1 \cdot 03 \mathrm{mmol} / \mathrm{l}$ occurred, but only one patient achieved normal calcium concentrations.

Before treatment seven patients had increased serum urea concentrations, 
Diagnoses, serum calcium concentrations before and after treatment with aminohydroxypropylidene diphosphonate, and concomitant treatments

\begin{tabular}{|c|c|c|c|c|c|c|}
\hline \multirow[b]{2}{*}{ Case No } & \multirow[b]{2}{*}{ Primary site diagnosis } & \multirow{2}{*}{$\begin{array}{c}\text { Serum calcium } \\
\text { concentration }(\mathrm{mmol} / \mathrm{l}) \\
\text { before treatment }\end{array}$} & \multirow{2}{*}{$\begin{array}{l}\text { Minimum serum calcium } \\
\text { concentration }(\mathrm{mmol} / \mathrm{l}) \\
\text { after treatment }\end{array}$} & \multirow{2}{*}{$\begin{array}{l}\text { No of days taken to reach } \\
\text { normal or minimum } \\
\text { concentration }\end{array}$} & \multicolumn{2}{|c|}{ Concomitant treatment } \\
\hline & & & & & Intravenous rehydration & Corticosteroids \\
\hline 1 & Adenocarcinoma of unknown primary site & $2 \cdot 92$ & $2 \cdot 08$ & 1 & Yes & Yes \\
\hline 2 & Large cell anaplastic lung cancer & $3 \cdot 48$ & $2 \cdot 18$ & 3 & Yes & Yes \\
\hline 3 & Breast cancer & $3 \cdot 23$ & $2 \cdot 29$ & 7 & No & No \\
\hline 4 & Squamous lung cancer & $3 \cdot 48$ & $2 \cdot 31$ & 1 & No & No \\
\hline 5 & Bladder cancer & $3 \cdot 12$ & $2 \cdot 30$ & 3 & Yes & No \\
\hline 6 & Breast cancer & 3.97 & $3 \cdot 10$ & 2 & Yes & No \\
\hline 7 & Breast cancer & $2 \cdot 84$ & $2 \cdot 61$ & 3 & Yes & No \\
\hline 8 & Small cell lung cancer & $3 \cdot 47$ & $2 \cdot 35$ & 5 & No & No \\
\hline 9 & Squamous tongue cancer & $3 \cdot 16$ & $2 \cdot 61$ & 5 & Yes & Yes \\
\hline 10 & Squamous lung cancer & 3.62 & $2 \cdot 76$ & 9 & No & No \\
\hline 11 & Breast cancer & $3 \cdot 18$ & $2 \cdot 36$ & 3 & Yes & No \\
\hline 12 & Breast cancer & $3 \cdot 37$ & $2 \cdot 56$ & 6 & No & No \\
\hline 13 & Squamous lung cancer & $3 \cdot 35$ & $2 \cdot 77$ & 6 & Yes & Yes \\
\hline 14 & Large cell anaplastic lung cancer & $3 \cdot 37$ & $2 \cdot 45$ & 6 & No & Yes \\
\hline 15 & Squamous lung cancer & $3 \cdot 58$ & $2 \cdot 59$ & 8 & Yes & No \\
\hline 16 & Squamous lung cancer & 3.55 & $2 \cdot 76$ & 4 & No & No \\
\hline
\end{tabular}

five of whom also had increased serum creatinine concentrations. After treatment the creatinine concentration in one and urea concentrations in three remained marginally abnormal. Transient fevers within one day of treatment occurred in three patients, but other side effects were not detected. The correction of hypercalcaemia was associated with an improvement in hypercalcaemic symptoms.

\section{Discussion}

Single infusions of $30 \mathrm{mg}$ aminohydroxypropylidene diphosphonate were not appreciably toxic and were effective alone or when used in combination with other treatments in most patients with malignant hypercalcaemia. Only one patient remained moderately hypercalcaemic, despite a substantial decrease in serum calcium concentrations. A possible confounding factor in interpreting our results was the treatment with corticosteroids in five patients, but corticosteroids probably have a negligible effect on hypercalcaemia caused by solid tumours. ${ }^{8}$

The time in our study taken to reach normal or minimum serum calcium concentrations, whichever was earlier, was similar to that taken in studies that used daily lower dose infusions of aminohydroxypropylidene diphosphonate. ${ }^{34}$ This contrasts with the rapid early decrease in calcium concentrations seen when a combination of a calcitonin and aminohydroxypropylidene diphosphonate is used. ${ }^{s}$

Though intravenous rehydration is desirable because of the renal effects of hypercalcaemia,' it is valuable to be able to correct hypercalcaemia with a single two hour intravenous infusion of $\mathbf{3 0}$ mg aminohydroxypropylidene diphosphonate. Thus this treatment could be effective and convenient for ambulatory patients who have mild to moderate asymptomatic hypercalcaemia and who are not dehydrated. Intravenous rehydration should remain the first step of treatment for patients who have symptomatic hypercalcaemia or more than moderate biochemical hypercalcaemia.
Our results suggest that single high dose infusions of aminohydroxypropylidene diphosphonate could replace conventional daily lower dose infusions. This would lessen the risk of thrombophlebitis at the infusion site ${ }^{4}$ and be advantageous in terms of cost. The optimum frequency of treatment with high doses of aminohydroxypropylidene diphosphonate is uncertain and needs further study.

A critical determinant of long term normocalcaemia is the control of cancer with specific anticancer treatment, but for patients whose cancers cannot be controlled a high dose infusion of aminohydroxypropylidene diphosphonate every week or alternate week may help to control distressing hypercalcaemia.

Aminohydroxypropylidene diphosphonate for intravenous use was supplied by Ciba-Geigy Pharmaceuticals.

\section{References}

1 Fisken RA, Heath DA, Bold AM. Hypercalcaemia-a hospital survey. Qf Med 1980;49:405-18. 2 Wilkinson $\mathrm{R}$. Treatment of hypercalcaemia associated with malignancy. BrMed f 1984;288:812-3.

3 Sleeboom HP, Bijoet OLM, Van Oosterom AT, Gleed JH, O'Riordan JLH. Comparison of intravenous (3-amino-1-hydroxypropylidene)-1, 1-biphosphonate and volume repletion in tumour-induced hypercalcaemia. Lancet 1983;i:239-43.

4 Ralston SH, Gardner MD, Dryburgh FJ, Jenkins AS, Cowan RA, Boyle IT. Comparison of aminohydroxypropylidene diphosphonate, mithramycin and corticosteroids/calcitonin in treatment of cancer-associated hypercalcaemia. Lancet 1985;ii:907-10.

5 Ralston SH, Alzaid AA, Gardner MD, Boyle IT. Treatment of cancer associated hypercalcaemia with combined aminohydroxypropylidene diphosphonate and calcitonin. $\mathrm{Br}$ Med $\mathcal{F}$ 1986;292: 1549-50.

6 Cantwell B, Harris AL. Single high dose aminohydroxypropylidene diphosphonate infusions to treat cancer-associated hypercalcaemia. Lancet 1986;i:165-6.

7 Anonymous. Correcting the calcium [Editorial]. Br Med f 1977;i:598.
8 Percival RC, Yates AJP, Gray RES, Neal FE, Forrest ARW, Kanis JA. Role of glucocorticoids in management of malignant hypercalcaemia. Br Med f 1984;289:287.

9 Heller SR, Hosking D.J. Renal handling of calcium and sodium in metastatic and non-metastatic malignancy. BrMed $\mathcal{F}$ 1986;292:583-6.

(Accepted 19 January 1987)
Hydrophobia during the past few weeks of abnormally hot weather, says an Odessa correspondent, appears to have become epidemic. "Our Pasteurian Hospital here," he adds, "is overwhelmed with cases. The operating room is crowded during six hours every day, with continuously succeeding batches of patients from every quarter. Within the last ten days, besides local cases, there have arrived for treatment here forty-seven patients, twenty from Kieff bitten by rabid dogs, fifteen from Podolia bitten by a rabid wolf, and twelve Montenegrins also suffering from mad wolf bites. There are seven Turkish cases under treatment, and 120 others from various neighbouring districts. Each patient in inoculated twice a day for ten, and in some cases for twenty, consecutive days, so that Dr. Gamalea and his two lady assistants have just now their hands full. The authorities here seem to have taken alarm at the extraordinary increase of rabies, and are taking measures for the destruction day after day of the stray dogs in different quarters of the city." Within twenty-four hours of writing, the correspondent learns that three deaths have occurred among the patients in the bacteriological station there; the victims being a man and two boys who formed part of a contingent of fourteen Caucasians bitten by a rabid she-wolf. The deceased lad is said to have been under treatment for nineteen days, and to have been inoculated thirty-eight times. Dr. Gamalea would not guarantee the efficacy of the Pasteur system in the cure of wolf-bitten patients unless they were in his hands not later than three days after being bitten. This was of course impossible in the case of the deceased Caucasians, who could not reach the Odessa station within a week. (British Medical fournal 1887;ii:524.) 